\title{
Seed longevity of Buchanania siamensis in reclaiming salt-affected areas in Thailand
}

\author{
YONGKRIAT KU-OR ${ }^{1}$, NISA LEKSUNGNOEN ${ }^{1,2, \boldsymbol{v}}$, CHATCHAI NGERNSAENGSARUAY ${ }^{3}$, \\ TUSHAR ANDRIYAS ${ }^{4}$ \\ ${ }^{1}$ Department of Forest Biology, Faculty of Forestry, Kasetsart University. 50 Phahonyothin Rd, Lat Yao, Chatuchak, Bangkok 10900, Thailand \\ ${ }^{2}$ Center for Advanced Studies in Tropical Natural Resources, National Research University, Kasetsart University. 50 Phahonyothin Rd, Lat Yao, \\ Chatuchak, Bangkok 10900, Thailand."email: fforns1@ku.ac.th, yongkriat1027@gmail.com \\ ${ }^{3}$ Department of Botany, Faculty of Science, Kasetsart University. 50 Phahonyothin Rd, Lat Yao, Chatuchak, Bangkok 10900, Thailand \\ ${ }^{4}$ Post-Doctoral Fellow, Department of Environmental Science, Chulalongkorn University. 254 Payathai Rd., Wang Mai, Pathumwan, Bangkok 10330,
} Thailand

Manuscript received: 2 December 2019. Revision accepted: 24 January 2020.

\begin{abstract}
Ku-or Y, Leksungnoen N, Ngernsaengsaruay C, Andriyas T. 2020. Seed longevity of Buchanania siamensis Miq. in reclaiming salt-affected areas in Thailand. Biodiversitas 21: 743-747. Inland salinity is a grave threat to soil fertility as it causes loss of arable land. Salt-tolerant species, such as Buchanania siamensis Miq., can be used for the reclamation of land affected by salinity. We investigated the appropriate conditions to store the seeds of $B$. siamensis and the storage duration after which the seeds can still germinate. Storage methods included cooling at $4^{\circ} \mathrm{C}$ and storing at room temperature (between $25-30^{\circ} \mathrm{C}$ ). Seeds kept at $4{ }^{\circ} \mathrm{C}$ had low germination $(6.75 \% \pm 1.71$ ), with longevity of only up to a week, compared to seeds stored at room temperature, which had germination of $94 \% \pm 4.00$ and could be stored for more than 200 days. Seed-longevity test was conducted at 14 levels (the number of storage days). Germination was reduced by $50 \%$ after 3.5 months, indicating that the seed could only be stored for the short term. The seeds were classified as having an intermediate behavior in which the germination increased exponentially with increasing seed moisture content. We recommend that seeds be stored at a temperature between 25 and $30^{\circ} \mathrm{C}$, with sowing done within 3.5 months to obtain germination at or above $50 \%$.
\end{abstract}

Keywords: Germination, intermediate behavior, seed moisture content, storage duration

\section{INTRODUCTION}

Salt-affected areas are a worldwide problem. Thailand has also been experiencing this problem for many decades and consequently suffering a reduction in area under agriculture (Leksungnoen 2017; Arunin and Pongwichian 2015). Inland salinity is found mostly in the northeastern part of Thailand and is mainly attributable to the existence of salt rocks in the parent material, up-welled to the surface as a result of long-term salt mining (Leksungnoen 2017). In areas with low salinity levels (less than 4 deciSeimen per meter or $\mathrm{dS} / \mathrm{m}$ ), yields of most crops reportedly decrease by 50\% (Arunin and Pongwichian 2015). Salinity levels in northeastern Thailand have been reported to be as high as 40-60 dS/m (Leksungnoen 2017), conditions under which only a few species can survive. However, Buchanania siamensis Miq. is one salt-tolerant species that can thrive under extreme salinity levels (Leksungnoen et al. 2016). This species has been reportedly found in areas affected by salinity for more than 30 years (Smitinan 1990), but researchers have yet to exploit its full potential and conditions for natural regeneration.

Buchanania siamensis Miq. is a $5-10 \mathrm{~m}$ high tree species, belonging to the Anacardiaceae family, and shares a close genetic resemblance with cashew nut (Anacardium occidentale L.) (Kubitzki 2011). It is a rare species native to the open deciduous forests and is found in the alluvial plains, at an altitude between 50-200 m (Chayamarit and
Staples 2010). Its young leaves are sour in taste and can be used as a food source by humans, whereas birds consume its fresh fruit and disperse seeds for regeneration at distances far from the mother plant. In addition, the local people have been using it as a medicine to treat women suffering from leucorrhoea (Chuakul et al. 2002). Its stems and roots help cure food poisoning and fever, whereas its bark can be used to treat gingivitis, aphthous stomatitis, and infection caused by herpes simplex virus (Khumkrathok and Klinhom 2001). Recently, it has been reported that the high levels of antioxidants found in extracts from the stems and leaves can be used in patients suffering from cancer (Yodsaoue et al. 2017). Moreover, the gum derived from the bark of a closely related species, B. cochinchinensis, has been used in pharmaceutical applications, such as binders in tablets, emulsifiers, and controlled release agents (Gaikwad et al. 2013). B. lanzan, another related species with antimicrobial properties, has been reported to heal wounds (Pattnaik et al. 2013).

Given its potential in reclaiming salt-affected lands and the various health benefits, $B$. siamensis should be intensively studied with regards to its reproductive system, beginning from germination. Recently, Leksungnoen et al. (2016) and Leksungnoen (2017) studied the seed germination of B. siamensis and reported germination between $60 \%$ and $70 \%$ under extremely high salinity of up to $35 \mathrm{dS} / \mathrm{m}$ (close to oceanic water), whereas, under normal conditions, germination was around $90 \%$. Therefore, this 
species was highly recommended for the reclamation of areas affected by salinity. The first step in reclamation is to obtain seedlings, which can either be through vegetative reproduction, such as cuttings, grafting, and tissue culture, or through sexual reproduction, i.e., from the seed. With regards to seed reproduction, to our knowledge, the seed storage behavior and life expectancy of B. siamensis has never been reported. Therefore, the objectives of this study were (i) to determine the germination following seed storage under cold conditions $\left(4^{\circ} \mathrm{C}\right)$ and room temperature conditions $\left(25-30^{\circ} \mathrm{C}\right)$ and (ii) to investigate how long the seeds can be stored under these conditions to guarantee an acceptable germination rate. The information from this study will be used to support the decision planning in reclaiming salt-affected areas in terms of how to store the seeds based on the ease, convenience, and cost of storing for the farmers and for how long would the seeds be viable.

\section{MATERIALS AND METHODS}

\section{Seed collection}

Seeds of B. siamensis were collected from Kam Tale So district, Nakhon Ratchasima province (1458'33.9" N $\left.101^{\circ} 56{ }^{\prime} 41.7^{\prime \prime} \mathrm{E}\right)$, Thailand. The soil in the area has been affected by salinity for more than 30 years, with several attempts by the government to reclaim the area by planting both exotic and native tree species. However, these trees were not able to tolerate moderate to high but not extremely high salt concentration measured in the Kam Tale So area (up to $64 \mathrm{dS} / \mathrm{m}$ on the soil surface during the dry season). In addition, there has been a gradual expansion in the area affected by salinity due to lack of vegetation cover with a direct result being the upwelling of groundwater to the soil surface. Therefore, reclamation of such salt-affected areas through extremely salt-tolerant species is an urgent task. The total affected area is around 16 ha, with the mother plants of B. siamensis clustered within an area of 1 ha. Ten mother trees were randomly selected from the 1 ha plot to ensure the genetic diversity of this rare species (Falk and Holsinger 1991), with around 100 seeds obtained per tree. The tree, leaves, flowers, fruits, and seeds from this species are shown in Figure 1. Seeds were hand-picked in late March 2016 and processed according to the steps outlined in Leksungnoen et al. (2016). Only fully mature fruits (dark red exocarp) were selected and were cleaned with water to remove the green flesh. The seeds thus obtained were cleaned and air-dried overnight before they were stored and tested for longevity.

\section{Seed longevity}

Seed longevity indicates the duration for which seed can survive and also the storage time. It is measured by recording the germination across a period of time (7 months during this study). Seeds were kept in a plastic box with a tight seal. A two-factor experiment was laid out as a completely randomized design (CRD). The first main factor was the storage method (two levels): (i) conventional method by cooling the seed at $4{ }^{\circ} \mathrm{C}$ (in a domestic refrigerator) at a relative humidity $(\mathrm{RH})$ between $30-40 \%$
(Roos 1989) and (ii) adaptation method by storing the seed at room temperature (varying between $25^{\circ} \mathrm{C}$ and $30^{\circ} \mathrm{C}$ ), with a RH between $60-70 \%$. The second main factor was the duration of storage (14 levels in days; chosen as 1,7 , 14, 21, 28, 35, 42, 49, 56, 86, 116, 146, 176, and 206 days. Seeds under both conditions were kept in tightly-seal plastic boxes to ensure the seed dryness.

A total of 100 seeds were used with 4 replications (25 seeds in each treatment combination, resulting in a total of 28 combinations). Each of the 25 seeds was placed in a germination box $(0.5 \mathrm{~L})$ on a filter paper (Grade 1 Whatman ${ }^{\circledR}$ qualitative filter paper, GE Healthcare BioScience, Pittsburgh, PA, USA) and $20 \mathrm{~mL}$ of filtered water was added to each box. All the boxes were kept in a germination chamber maintained at a temperature of $25 \pm$ $3^{\circ} \mathrm{C}$ and $\mathrm{RH}$ between $60 \%$ and $70 \%$. No light was allowed to enter the setup for the duration of the experiment. A seed was said to have germinated based on the outlines of the International Seed Testing Association (ISTA, 2017), i.e., when a radicle was observed through the naked eye, within a period of 30 days (Leksungnoen 2016). The total germination after 30 days was calculated as a percentage given by the formula below:

Total germination $(\%)=($ Number of germinated seeds within 30 days $)$ /Total number of seeds tested $(25$ seeds $) \times 100$

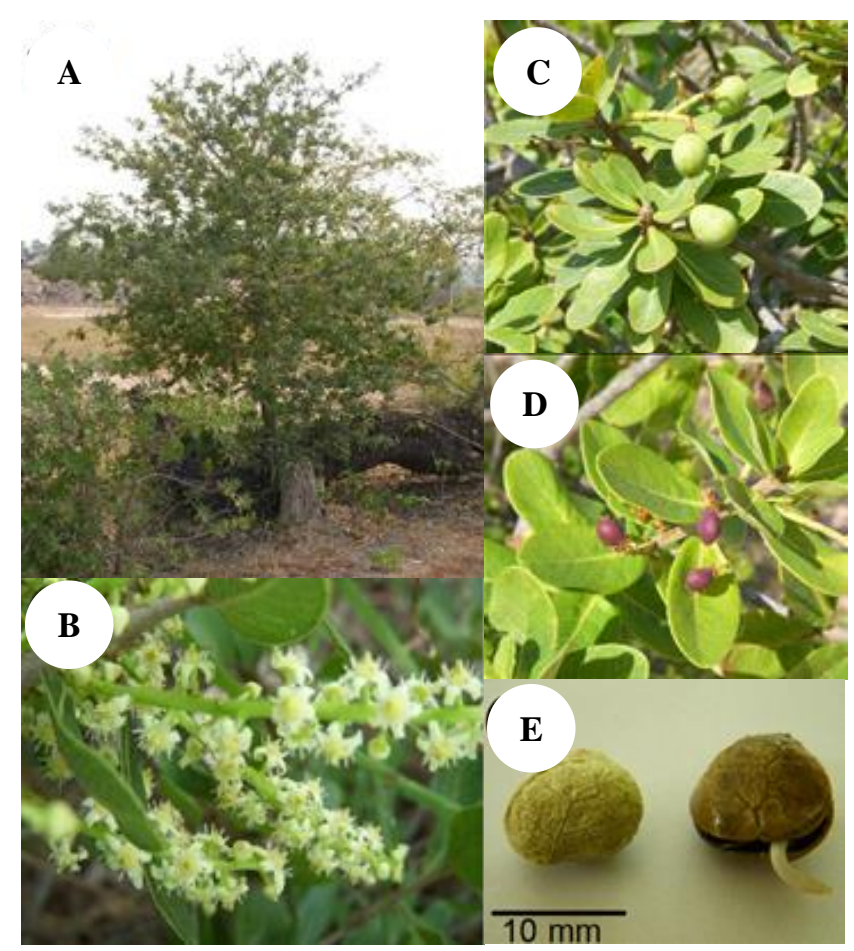

Figure 1. Morphological characteristics of Buchanania siamensis Miq. including (A) tree, (B) flowers blooming during the months from December to February, (C) fresh fruit with one hard seed (drupe); unripe fruits with the green color (during February to April), (D) ripen fruits that are initially red and turn black when dry, with a green-colored flesh mesocarp (during March to May), and (E) a heart-shaped seed and radicle intrusion during germination 
Time for seed germination to reduce by $\mathbf{5 0 \%}\left(\mathbf{T}_{\mathbf{5 0}}\right)$

The time taken for the germination to reduce by $50 \%$ $\left(\mathrm{T}_{50}\right)$ compared to the first day of germination was calculated from a scatter plot between the duration of storage (on the $\mathrm{X}$-axis) and total germination (on the $\mathrm{Y}$ axis). To explain the relationship between the duration of storage and total germination, the best fit curve was determined, as indicated by the highest coefficient of determination $\left(\mathrm{R}^{2}\right)$. The time (in days) after which the total germination was reduced by $50 \%$ is used to indicate the optimum length of storage time, i.e., the time after which at least $50 \%$ germination was guaranteed.

\section{Seeds moisture}

Seed moisture is one of the most important factors affecting both seed storage and germination. Seeds from all the 10 mother trees were mixed (around a 100 seeds each per mother tree). Seven seeds were then randomly selected to test for their moisture content as B. siamensis seeds are quite large. For each combination of storage method and duration $(2 \times 14=28$ combinations $), 4$ replicates of 7 seeds were used. In this study, seed moisture was measured according to the guidelines listed in the ISTA (2017) manual. A wet weight basis was used to calculate the seed moisture in this study. Seeds were weighed (wet weight) before being oven-dried at a temperature of $103^{\circ} \mathrm{C} \pm 3$ for $17 \pm 1 \mathrm{hrs}$ and weighed again (dry weight). Seed moisture was then calculated using the formula given below:

Seed moisture $(\%)=$ Wet weight $(\mathrm{g})$-Dry weight $(\mathrm{g}) /$ Wet weight $(\mathrm{g}) \times 100$

\section{Data analysis}

This experiment was conducted using a two-way factorial CRD; the two factors being storage method and duration of storage. The analysis of variance (ANOVA) was used to compare the mean differences between the germination percentage under different storage methods and durations using the $\mathrm{R}$ software. Pairwise comparisons were tested using the least square difference (LSD) method at an $\alpha$ level of $5 \%$.

\section{RESULTS AND DISCUSSION}

The seeds of B. siamensis are heart-shaped with a mean width of $10.45 \pm 1.09 \mathrm{~mm}$, mean length of $9.68 \pm 1.16 \mathrm{~mm}$. Seed dry weight was $8.85 \pm 0.50 \mathrm{~g}$ with initial seed moisture of $10.29 \pm 0.32 \%$ (as calculated from 100 seeds). Seed longevity was examined through a germination test conducted over a period of 7 months for the two types of storage methods. The results clearly indicated that the germination of seeds stored in the fridge (at $4^{\circ} \mathrm{C}$ ) was very low $(6.75 \pm 1.71 \%)$, when compared to the seeds stored at room temperature varying between $25-30^{\circ} \mathrm{C}(94.00 \pm$ $4.00 \%$ ), on day 1 (i.e., seeds that germinated right after they were harvested). After 7 days, no germination was observed in the seeds that were stored in the fridge. In other words, the seeds stored at $4^{\circ} \mathrm{C}$ lost their potential to germinate within a week. Therefore, the seed longevity test was conducted only on seeds stored at room temperature over various time spans $(1,7,14,21,28,35,42,49,56,86$, $116,146,176$, and 206 days). The results from a one-way ANOVA, which compared the mean germination rate over various durations, were analyzed instead of a two-way ANOVA (Table 1).

As indicated in Tables 1 and 2, the total germination significantly decreased with the duration of storage time. The maximum germination was recorded on the first day after the harvest (94\%). After that, a significant drop was observed at day 56 (total germination of $67 \%$ ) compared to days 1-49 (total germination reducing from 94 to $82 \%$ ). The germination gradually decreased over time until day 206 , when its value was reduced to $5 \%$. Not only did the total germination decrease with an increase in the storage duration, but the first day of germination was also delayed (from day 5 to day 20 for a storage duration of 1 and 206 days, respectively). Seed longevity can be studied in different ways and determining it from germination is one of the simplest and most widely used methods (ISTA, 2017). Seed storage behavior and storage conditions play an important role in enhancing seed longevity. Generally, seeds of tropical trees germinate within 14 days (Hong et al. 1996), but for B. siamensis, after harvesting, the seeds germinated on day 5 , but the germination was delayed to day 20 , when the seeds were stored for 206 days.

The duration of time after which seed germination reduced by $50 \%\left(\mathrm{~T}_{50}\right)$ was 105 days, as calculated from the best-fit equation (see Figure 2 ). The $\mathrm{R}^{2}$ value of the derived equation was high (0.9689) with a very low standard error of regression ( $\mathrm{S}$ ), as indicated by an average distance of data points from the fitted line of about $3 \%$. This indicated that the equation was robust for estimating the $\mathrm{T}_{50}$ value. The optimum storage duration for $B$. siamensis that would still result in germination of at least $50 \%$ was determined as approximately 3.5 months. This is considered as a shortterm seed storage behavior according to Hong et al. (1996), who indicated that seed viability of up to 18 months is classified as a short-term seed storage, while 18 months- 6 years is medium-term seed storage, while seeds that can be stored for more than 10 years fall under the long-term seed storage.

We found that the appropriate storage conditions for $B$. siamensis were at room temperature $\left(25-30^{\circ} \mathrm{C}\right)$, which is convenient and economically viable for most farmers. Storing the seeds of $B$. siamensis at $4^{\circ} \mathrm{C}$ resulted in very low germination with longevity for only a week. Walters et al. (2013) suggested that when seeds are stored at cold temperatures, ice crystals can gradually form, leading to tissue damage and seed mortality. This could be the reason as to why the seeds stored at cold temperatures in this study, had shorter longevity compared to the seeds maintained at temperatures between $25-30^{\circ} \mathrm{C}$ (as the seeds could germinate after 7 months of storage).

Even though the seeds of $B$. siamensis are unlikely to be stored at temperatures maintained conventionally (below$20^{\circ} \mathrm{C}$ ) due to dryness and ice crystal damage, a cryopreservation method could be a storage option for seeds showing recalcitrant and intermediate behavior (Walters et al. 2013). In such a procedure, the seed embryos or the whole seed is rapidly cooled to ultra-low 
temperature $\left(-196^{\circ} \mathrm{C}\right)$ using liquid nitrogen, to prevent the freezing of water in the seed (Hong et al. 1996). This technique has been reported to conserve seeds showing an intermediate storage behavior, such as that of B. lanzan, for which the viability after cryopreservation decreased by only $22 \%$ from the initial germination percentage (Malik et al. 2011). Further studies can look into storage conditions of $B$. siamensis with the cryopreservation technique in order to enhance their viability. However, this technique is expensive and requires specialized infrastructure and therefore, is economically less viable, especially for small and medium-scale farmers.

Table 1. One-way ANOVA test for differences in mean germination and seed moisture under 14 seed storage with 4 replicates $(\mathrm{N}=4)$, of $B$. siamensis seeds, collected from the saltaffected areas in Kam Tale So, Nakhon Ratchasima, Thailand

Germination ANOVA test

\begin{tabular}{|c|c|c|c|c|c|}
\hline $\begin{array}{l}\text { Source } \\
\text { variation }\end{array}$ & df & $\begin{array}{l}\text { Sum } \\
\text { square }\end{array}$ & $\begin{array}{l}\text { Mean } \\
\text { square }\end{array}$ & $\begin{array}{l}\text { F- } \\
\text { value }\end{array}$ & P-value \\
\hline $\begin{array}{lr}\text { Seed } & \text { storage } \\
\text { duration } & \text { (14-time } \\
\text { interval) } & \end{array}$ & 13 & 51611 & 3970 & 76.72 & $<0.0001$ \\
\hline Residuals & 42 & 2174 & 52 & & \\
\hline Total & 55 & 53785 & 4022 & & \\
\hline \multicolumn{6}{|c|}{ Seed moisture ANOVA test } \\
\hline $\begin{array}{l}\text { Source of } \\
\text { variation }\end{array}$ & df & $\begin{array}{l}\text { Sum } \\
\text { square }\end{array}$ & $\begin{array}{l}\text { Mean } \\
\text { square }\end{array}$ & $\begin{array}{c}\text { F- } \\
\text { value }\end{array}$ & P-value \\
\hline $\begin{array}{l}\text { Seed storage } \\
\text { duration (14-time } \\
\text { interval) }\end{array}$ & 13 & 4.392 & 0.3378 & 18.41 & $<0.0001$ \\
\hline Residuals & 42 & 0.771 & 0.0184 & & \\
\hline Total & 55 & 5.163 & 0.3562 & & \\
\hline
\end{tabular}

Table 2. Test for seed longevity for Buchanania siamensis Miq. using total germination over various lengths of storage duration (days) at room temperature (varying between $25-30^{\circ} \mathrm{C}$ ) with the respective seed moisture content $(\%)$.

\begin{tabular}{lcc}
\hline $\begin{array}{c}\text { Storage duration } \\
\text { (days) }\end{array}$ & $\begin{array}{c}\text { Total seed } \\
\text { germination }(\%) \pm \\
\text { SD }\end{array}$ & $\begin{array}{c}\text { Seed moisture } \\
(\%) \pm \text { SD }\end{array}$ \\
\hline 1 & $94.00 \pm 4.00^{\mathrm{a}^{\mathrm{*}}}$ & $10.35 \pm 0.13^{\mathrm{ab}}$ \\
7 & $91.00 \pm 6.00^{\mathrm{ab}}$ & $10.17 \pm 0.09^{\mathrm{bc}}$ \\
14 & $92.00 \pm 6.53^{\mathrm{ab}}$ & $10.47 \pm 0.17^{\mathrm{a}}$ \\
21 & $93.00 \pm 6.00^{\mathrm{a}}$ & $10.14 \pm 0.09^{\mathrm{c}}$ \\
28 & $93.25 \pm 3.77^{\mathrm{a}}$ & $10.13 \pm 0.14^{\mathrm{c}}$ \\
35 & $86.00 \pm 7.66^{\mathrm{ab}}$ & $10.33 \pm 0.07^{\mathrm{ab}}$ \\
42 & $85.25 \pm 4.99^{\mathrm{ab}}$ & $10.20 \pm 0.09^{\mathrm{bc}}$ \\
49 & $82.00 \pm 5.16^{\mathrm{b}}$ & $10.19 \pm 0.11^{\mathrm{bc}}$ \\
56 & $67.00 \pm 12.81^{\mathrm{c}}$ & $10.19 \pm 0.10^{\mathrm{bc}}$ \\
86 & $54.00 \pm 8.33^{\mathrm{d}}$ & $10.31 \pm 0.11^{\mathrm{abc}}$ \\
116 & $37.00 \pm 12.81^{\mathrm{e}}$ & $10.17 \pm 0.20^{\mathrm{bc}}$ \\
146 & $24.00 \pm 3.27^{\mathrm{f}}$ & $10.28 \pm 0.26^{\mathrm{abc}}$ \\
176 & $23.00 \pm 2.00^{\mathrm{f}}$ & $9.78 \pm 0.05^{\mathrm{d}}$ \\
206 & $5.00 \pm 7.57^{\mathrm{g}}$ & $9.29 \pm 0.13^{\mathrm{e}}$ \\
\hline
\end{tabular}

Note: *The lowercase letters indicate the mean difference in total seed germination over the various levels of storage duration when using a pairwise least square difference (LSD) at a significance level of $95 \%$. N is the number of replicates with 25 seeds in each replicate group.

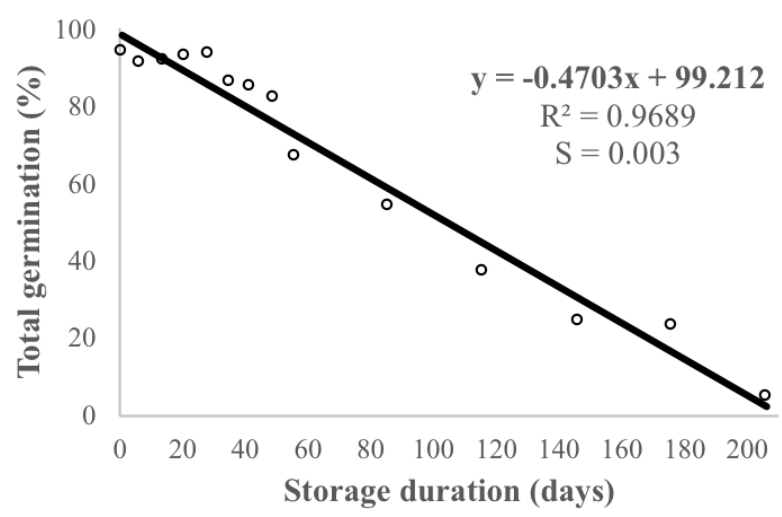

Figure 2. Scatter plot between the storage duration and total germination percentage for $B$. siamensis Miq. The black continuous line indicates the best fit curve. From the equation, it was found that the duration of time leading to the seed germination reducing by $50 \%$ ( $\left.\mathrm{T}_{50}\right)$ was 105 days ( 3.5 months)

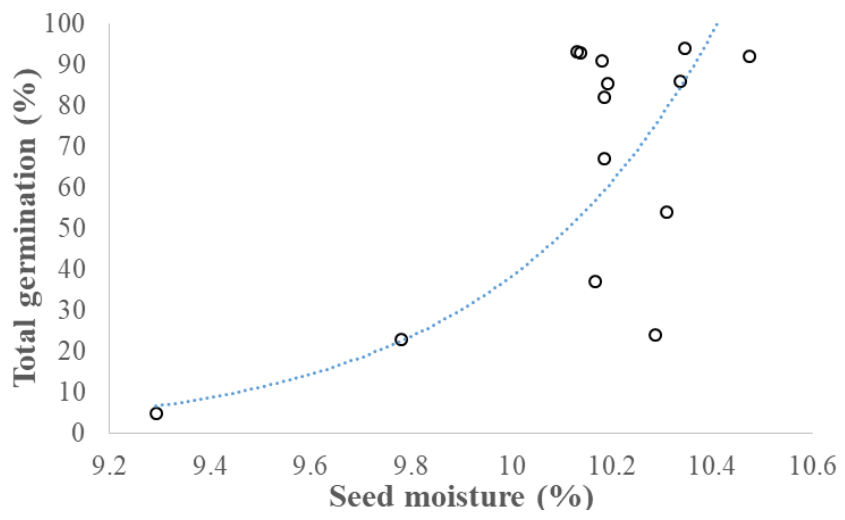

Figure 3. The exponential best fit for the relationship between seed moisture and total germination of $B$. siamensis Miq. seeds, stored at room temperature $\left(25-30^{\circ} \mathrm{C}\right)$, over a period of 7 months

Seed moisture plays an important role in the storage as well as germination, as the rate of imbibition (the first step in germination when the water is absorbed into the seed) depends on the level of seed moisture. The moisture content was measured between $9.70-10.44 \%$ (Table 1) and seed germination decreased exponentially with decreasing seed moisture content. The correlation between total germination at a specific level of storage duration and seed moisture was around 0.754 (Figure 3 ). The seeds could germinate optimally well when the seed moisture was more than $10 \%$. However, at low germination percentages between $20-50 \%$, the seed moisture was still above $10 \%$. Seed germination drastically decreased $(<20 \%)$ when seed moisture content was below $10 \%$, which correlated with a storage time of 176 days (about 6 months).

Generally, three seed storage behaviors are observed, depending on the seed moisture content, which includes orthodox, recalcitrant, and an intermediate behavior (in between orthodox and recalcitrant) (Hong et al. 1996). Seeds that are able to germinate with high moisture content (between 15-20\%) are considered recalcitrant and are 
relatively difficult to store using convention methods. Orthodox seeds, on the other hand, can lower their moisture content to less than $5 \%$ and still germinate. Intermediate seeds have seed moisture content that is between orthodox and recalcitrant (10-12.5\%) (Hong et al. 1996). As the seed storage behavior of B. siamensis was found to be between recalcitrant and orthodox, we classified it as having an intermediate behavior. Most of the recalcitrant seeds generally have a large seed, are shortlived (typically perish within weeks), and need water to survive (Walters et al. 2013). Such seeds have a shelf life of not more than 45 days, when stored at ambient temperatures (Malik et al. 2011). During this study, the seeds of B. siamensis could be stored for up to 7 months, indicating that its behavior was not recalcitrant. According to Hong et al. (1996), seeds showing an intermediate storage behavior can have seed moisture between 10$12.5 \%$, and for the B. siamensis seeds, it was measured between $9.29-10.44 \%$. For the successful germination of $B$. siamesis, seed moisture content should be at least $9 \%$ or more which at this level is higher than the desiccation that an orthodox seed can tolerate (less than 5\%) (Hong et al. 1996). Therefore, the seeds of B. siamensis cannot be classified as having an orthodox behavior.

Most seeds from the species belonging to the Anacardiaceae family, such as mango (Mangifera indica), cashew nut (Anacardium occidentale), (Teichman et al. 1988), and Bouea oppositifolia (Lestari 2013), are believed to be recalcitrant, in which the germination must start within a week, as chances for germination decrease due to rapid decrease in seed moisture. However, B. lanzan, a closely related species to $B$. siamensis, also showed an intermediate behavior with longevity at ambient temperatures between $25-34^{\circ} \mathrm{C}$ of up to 11 months (Malik et al. 2011), while the longevity of B. siamensis seed in this study was around 7 months. In rare cases, the seeds of some Anacardiaceae species, such as B. arborescens, have also been classified as orthodox (Lestari 2013).

In conclusion, seeds of $B$. siamensis indicated an intermediate behavior with the seed moisture between 9.29$10.44 \%$. We recommend storage conditions maintained at room temperature $\left(25-30^{\circ} \mathrm{C}\right)$, but only for 3.5 months, as this is the duration after which the seed viability decreased to below $50 \%$. In other words, for the purposes of reclamation of areas affected by salinity, seeds should be stored for a relatively short time (3-4 months) before germinating and planting in the salt-affected areas. However, if the longevity of $B$. siamensis is to be enhanced, seeds can also be stored using cryopreservation techniques, but at an increased cost of storage.

\section{ACKNOWLEDGEMENTS}

This research is supported by the Graduate Program Scholarship from The Graduate School, Kasetsart
University, Bangkok, Thailand. The Office of the Higher Education Commission, The Thailand Research Fund (TRF), and Center for Advanced Studies in Tropical Natural Resources, National Research University, Kasetsart University, Bangkok, Thailand.

\section{REFERENCES}

Arunin S, Pongwichian P. 2015. Salt-affected soils and management in Thailand. Bull Soc Water Sci 69 (5): 319-25.

Chayamarit K, Staples G. 2010. Flora of Thailand 10 (3): Anacardiaceae and Convolvulaceae. Forest Herbarium, Department of National Park, Wildlife and Plant Conservation, Bangkok.

Chuakul W, Saralamp S, Boonpleng A. 2002. Medicinal plants used in the Kutchum District, Yasothon Province, Thailand. Thai J Phytopharm 9: $22-49$.

Gaikwad N, Kulkarni G, Gowthamarajan K, Kumar E. 2013. Development of controlled release spheroids using Buchanania cochinchinesis Gum. J Excipients Food Chem 4 (1): 4-11.

Falk DA, Holsinger KE. 1991. Genetics and Conservation of Rare Plants. Oxford University Press, New York, USA.

Hong TD, Ellis RH. 1996. A Protocol to Determine Seed Storage Behaviour. IPGRI Technical Bulletin. Department of Agriculture, The University of Reading, UK.

ISTA [International Seed Testing Association]. 2017. International Rules for Seed Testing: Rule1999. International Seed Testing Association, Zurich, Switzerland.

Khumkrathok S, Klinhom U. 2001. Flora of Northeastern Thailand. Walia Rukhavej Botanical Research Institute, Mahasarakham University, Mahasarakham, Thailand.

Kubitzki K. 2011. The Families and Genera of Vascular Plants. Flowering Plants. Eudicots: Sapindales, Cucurbitales, Myrtaceae. Springer Science \& Business Media, New York.

Leksungnoen N, Uthairatsamee S, Na Takuathung C. 2016. Germination test on native salt-tolerant seeds (Buchanania siamensis Miq.) collected from natural saline and non-saline soil. J For 3 (3): 1-14.

Leksungnoen N. 2017. Reclaiming saline areas in Khorat Basin (Northeast Thailand): Soil properties, species distribution, and germination of potential tolerant species. Arid Land Res Manag 31 (3): 235-52.

Lestari DA. 2013. Characterization of external morphology on various seeds in Purwodadi Botanic Garden. Proceeding International Conference of The 4th Green Technology; Maulana Malik Ibrahim State Islamic University, Malang, East Java, Indonesia, 2013 Nov 9.

Malik SK, Chaudhury R, Kalia RK, Dulloo E. 2011. Seed storage characteristics and cryopreservation of genetic resources of tropical underutilized fruits in India. Acta Hortic 918: 189-198.

Pattnaik A, Sarkae R, Sharma A, Yadav KK, Kumar A, Roy P, Mazumder A, Karmakar S, Sen T. 2013. Pharmacological studies on Buchanania Lanzan Spreng.-A focus on wound healing with particular reference to anti-biofilm properties. Asian Pac J Trop Biomed 3 (12): 967-74.

Roos EE. 1989. Long-Term Seed Storage. In: Janick J (ed) Plant Breeding Reviews: The National Plant Germplasm System of the United States. Timber Press, Portland, OR.

Smitinan T. 1990. Plant species occurrence in salt-affected area. Agric Sci 22 (4): 278-284.

Teichman IV, Robbertse PJ, Schoonraad E. 1988. The structure of the seed of Mangifera indica L. and notes on seed characters of the tribe Mangifereae (Anacardiaceae). South Afr J Bot 54 (5): 472-476.

Walters C, Christina W, Patricia B, Norman P, Kathryn K, Peter R. 2013. Preservation of recalcitrant seeds. Science 339 (6122): 915-916.

Yodsaoue O, Kamonwannasit S, Frangkrathok N. 2017. Antioxidant and anticancer activities of Buchanania siamensis Miq. stem and leaf extracts. J Sci Technol Ubon Ratchathani University, Special Issue September 2017: 13-16. 